Original Article

\title{
“A STUDY ON DRUG UTILIZATION PATTERN OF CEPHALOSPORINS IN GENERAL MEDICINE AND SURGICAL INPATIENT DEPARTMENT"
}

\author{
NAVEEN V. ${ }^{*}$, ABUBAKER SIDDIQ ${ }^{2}$, CHANDANA G. ${ }^{1}$ \\ ${ }^{1}$ Department of Pharmacy Practice, SJM College of Pharmacy, Chitradurga 577502, Karnataka, India, ${ }^{2}$ Department of Pharmacology, SJM \\ College of Pharmacy, Chitradurga 577502, Karnataka, India \\ Email: vaddinaveenkumar4747@yahoo.com
}

Received: 20 Jan 2018, Revised and Accepted: 08 Mar 2018

\begin{abstract}
Objective: Cephalosporins are a commonly used group of antibiotics in hospitals and healthcare facilities around the world. In the developed countries through the use of older cephalosporins is declining, that of the newer generations has increased. The objective of this study was to assess
\end{abstract} Drug Utilization Pattern of Cephalosporins in General Medicine and Surgical Inpatient Departments of tertiary care hospital.

Methods: The data of enrolled patients were collected from case records of admitted inpatients during the study period. The collected data was assessed by statistical analysis using descriptive analysis.

Results: A total of 110 inpatients were enrolled in the study. Out of 110 patients, males were $54.5 \%$ and females were $45.5 \%$. The results analyzed that the prescriptions are more with third-generation cephalosporins than fourth-generation cephalosporins.

Conclusion: The study concludes that $3^{\text {rd }}$ generation cephalosporins is widely used for treating various nosocomial infections.

Keywords: Cephalosporins, Drug utilization, Prescriptions, Antibiotics

(c) 2018 The Authors. Published by Innovare Academic Sciences Pvt Ltd. This is an open access article under the CC BY license (http://creativecommons.org/licenses/by/4.0/) DOI: http://dx.doi.org/10.22159/ijcpr.2018v10i3.27225

\section{INTRODUCTION}

Drugs today play an important role in protecting, maintaining and restoring one's health. Identifying, preventing, and resolving in the healthcare process. Drug utilization research can increase our understanding of how drugs are being used to estimate the numbers of patients exposed to specified drugs within a given time period [1]. Yet, the flip side is that the improper or inappropriate use of drugs can be harmful and could evoke new adverse symptoms, be the cause of patient's morbidity and even mortality. Cephalosporins are a commonly used group of antibiotics in hospitals and healthcare facilities around the world [2].

Ceftriaxone is one of the most commonly used antibiotics due to its high antibacterial potency, a wide spectrum of activity and low potential for toxicity [3]

As the medical practice changes in complexity and sophistication, the importance of patient education is being increasingly recognized as an essential component of high-quality medical care. "Patient education" refers to the educational experiences planned for the patient by professional personnel as a component of his care. Although the benefits patients gain from pharmacological intervention are valuable, the risks of drugs and consequences of inappropriate use cannot overlooked [4]. Patient education has a critical importance. From an ideal patient education, the physician may gain satisfaction in having an impact on the health of their patients, and they benefit from an enhanced relationship with their educated patients. Drug utilization studies aim to evaluate factors related to the prescribing, dispensing, administering and taking of medication, and its associated events. Prescription of drugs in a critically ill patient is complicated. The judicious use of medications can be lifesaving. The routine use of conventional drug dosage regimens may expose ICU patients to drug-related problems such as treatment failure, drug interactions and high risk of adverse drug reactions. Careful titration and monitoring of dosage regimens becomes imperative to ensure the ideal treatment outcome [5].

Antibiotics are the most frequently prescribed and misused drugs and there are reported concerns about the continuous indiscriminate and excessive use of antibiotics leading to the emergence of antibiotic-resistant organisms [6]. Monitoring antibiotic use with microbiology laboratory support can promote rational drug utilization, cut costs, halt inappropriate 3GC prescribing, and delay the emergence of resistant organisms [7].

Due to the widespread use of antibiotics in the health care system, the clinical isolates were developing resistance to different antibiotics [8]. This widespread and indiscriminate use of antimicrobial agents inevitably has resulted in the emergence of antibiotic-resistant pathogens. This practice of indiscriminate prescribing of AMAs also leads to ineffective and unsafe treatment, prolongation of illness, disease exacerbation, distress and harm to the patients. All these issues produced a great concern over the inappropriate and injudicious use of antimicrobial agents all over the world [9]. Cephalosporins generally cause few side effects. Common side effects mainly involve the digestive system with mild stomach cramps or upset, nausea, vomiting and diarrhea. These side effects are usually mild and go away with time [10]. Patient education programs to support patient participation in disease management have been proposed as an important strategy in limiting the growing burden of chronic diseases.

\section{Objectives}

1. To determine the frequency of drug usage of Cephalosporin antibiotics.

2. To assess the relationship between patient demographics and prescription pattern.

3. To assess the percentage of drugs prescribed by generic and brand name of cephalosporins.

\section{MATERIALS AND METHODS}

\section{Methodology}

This study was conducted at Drug Utilization Pattern of Cephalosporins in General Medicine and Surgical Inpatient Department of Basaveshwara Medical College Hospital and Research Centre, Chitradurga for a period of six months. This study was 
approved by the "Institutional Human Ethical Committee" of the S. J. M College of Pharmacy, Chitradurga. Thus the study was described as a prospective observational study. Age, gender, drugs used on admission, drugs commenced during a hospital stay, the reason for hospitalization, relevant medical history and relevant laboratory values were registered for all the patients.

For assessment of ADRs, only those ADR which were reported by the hospital staff were considered. Drug interactions were assessed by using Medscape Multi-drug Interaction Checker Application. Version: 3.2.2.

For patient Education assessment, list of 20 elements was prepared and patients were asked the same elements pre and post counseling, to assess the level of knowledge of patients related to their own drug therapy. Patient education was divided into 2 parts i.e. first 8 subdomains i.e. Name, Strength, Dose, Schedule, Administration, Expected Duration, Indication, Possible ADRs; and remaining 11 subdomains including: Minimum Required Duration, Drug Interactions, Food Interactions, Storage, Missed Dose, Benefits of Completing Therapy, Medication Adherence, Special Monitoring, Special Precautions (If Any) and Lifestyle Modifications.

\section{RESULTS}

\section{Demographic details}

Out of 110 patients enrolled during the study period, we found that males were $60(54.5 \%)$ and females were $50(45.5 \%)$. The results are summarized in table 1 .

\section{Distribution of the patients according to age}

From the analysed data we found that, the large number of patients were at the age group of more than $60 \mathrm{y}(29.1 \%)$, followed by 31-40 y (20.9\%), 21-30 у (19.1\%), 41-50 у (15.5\%), 51-60 (13.6\%),<20 y $(1.8 \%)$. The results are summarized in table 2.

Table 1: Distribution of patients according to gender

\begin{tabular}{lll}
\hline Gender & No. of patients & Percentage \\
\hline Male & 60 & 54.5 \\
Female & 50 & 45.5 \\
Total & 110 & 100 \\
\hline
\end{tabular}

Table 2: Distribution of the patients according to age

\begin{tabular}{lll}
\hline Age group & Frequency & Percentage \\
\hline Less than $20 \mathrm{y}$ & 2 & 1.8 \\
$21-30 \mathrm{y}$ & 21 & 19.1 \\
$31-40 \mathrm{y}$ & 23 & 20.9 \\
$41-50 \mathrm{y}$ & 17 & 15.5 \\
$51-60 \mathrm{y}$ & 15 & 13.6 \\
More than $60 \mathrm{y}$ & 32 & 29.1 \\
Total & 110 & 100 \\
\hline
\end{tabular}

\section{Percentage of different generations of cephalosporins prescribed}

In total 110 patients, Out of which 95 drugs belong to the $3^{\text {rd }}$ generation of cephalosporins of about $86.4 \%$, $1^{\text {st }}$ generation constitutes of about 11 drugs (10.0\%), $2^{\text {nd }}$ generation constitutes 3 drugs $(2.7 \%)$ and $4^{\text {th }}$ generation constitute 1 drug $(0.9 \%)$ out of 110 prescriptions. The results are summarized in table 3 .

Table 3: Distribution of the patients according to use of cephalosporins

\begin{tabular}{lll}
\hline Cephalosporins used & Frequency & Percentage \\
\hline $1^{\text {st }}$ generation & 11 & 10.0 \\
$2^{\text {nd }}$ generation & 3 & 2.7 \\
$3^{\text {rd }}$ generation & 95 & 86.4 \\
$4^{\text {th }}$ generation & 1 & 0.9 \\
Total & 110 & 100 \\
\hline
\end{tabular}

\section{Distribution according to comorbidity conditions}

In the study period, Out of 69 patients are admitted with Comorbidity conditions and 41 patients are not admitted with comorbidity conditions. The results are summarized in table 4 .

\section{Percentage of cephalosporin prescribed}

In total 110 patients total number of cephalosporins prescribed, Out of which 65 drugs belong to the ceftriaxone of about $59.1 \%$, cefotaxime of about 6 (5.4\%), followed by Cefaperazone, Sulbactam5drugs
(4.5\%), Cephalexin, Sulbactum4(3.6\%), Cefaperazone, Cefazolin, Cefuroxime $3(2.7 \%)$ Cefipime, Ceftaxidine $1(0.9)$. The results are summarized in table 5 .

\section{Comparision between brand vs generic prescriptions}

In brand vs generic drug analysis for overall 110 prescriptions for 110 patients in a study out of 110 prescriptions, 15 prescriptions were prescribed by generic names $13.6 \%$ and the rest 95 is prescribed by brand names $86.4 \%$. The results are summarized in table 6.

Table 4: Distribution of the patients on comorbidities

\begin{tabular}{lll}
\hline Co morbidity & Frequency & Percentage \\
\hline Yes & 69 & 62.7 \\
No & 41 & 37.3 \\
Total & 110 & 100 \\
\hline
\end{tabular}


Table 5: Percentage of cephalosporin prescribed

\begin{tabular}{|c|c|c|}
\hline Cephalosporins used & Frequency & Percent \\
\hline Cefaperazone & 3 & 2.7 \\
\hline Cefaperazone, Sulbactam & 5 & 4.5 \\
\hline Cefazolin & 3 & 2.7 \\
\hline Cefipime & 1 & 0.9 \\
\hline Cefotaxime & 6 & 5.4 \\
\hline Ceftriaxone & 9 & 8.2 \\
\hline Ceftazidine, Tazobactum & 1 & 0.9 \\
\hline Ceftriaxone & 65 & 59.1 \\
\hline Ceftriaxone-Sulbactum & 3 & 2.7 \\
\hline Ceftriaxone/cefotaxime & 1 & 0.9 \\
\hline Ceftriaxone/CefotaximeSulbactum & 1 & 0.9 \\
\hline Cefuroxime & 3 & 2.7 \\
\hline Cephalexin & 4 & 3.6 \\
\hline Cephalexin, Sulbactum & 4 & 3.6 \\
\hline Total & 110 & 100 \\
\hline
\end{tabular}

Table 6: Comparision between brand vs generic prescriptions

\begin{tabular}{lll}
\hline Brand/Generic & Frequency & Percent \\
\hline Brand & 95 & 86.4 \\
Generic & 15 & 13.6 \\
Total & 110 & 100 \\
\hline
\end{tabular}

Table 7: Average direct cost of prescription of patients

\begin{tabular}{lll}
\hline Cost analysis & Frequency & Percent \\
\hline Cephalosporin cost & 492.99 & 339.3 \\
Hospital cost & 671.82 & 287.07 \\
Total cost & 1172.99 & 558.54 \\
\hline
\end{tabular}

\section{Average direct cost of prescriptions}

The average cost of prescription for class of cephalosporins was 492.99 INR, for Hospital 671.82INR and the total cost was 1172.99 INR per prescription. The results are summarized in table 7.

\section{DISCUSSION}

The principle target of the drug utilization studies/research is to promote the rational prescribing of the drugs. Prescription gives insight into nature of the health care delivery system in drug utilization research. A prescription by a doctor may be taken as a reflection of physician's attitude to the disease and the role of the drug in its treatment. It also provides an insight into the nature of the health care delivery system.

The present prospective observational study was conducted to analyze the drug use of cephalosporins with the trend and their direct cost per prescription and also to assess percentage of drugs prescribed by generic and brand name of cephalosporins in study population to explore what proportion of the population is exposed to some of the more prevalently prescribed pharmaceuticals.

In our study, we have enrolled 110 patients among which males were 60 $(54.5 \%)$ and females were $50(45.5 \%)$. A similar study conducted by Kiran $B$ et al.,In their demographic profile, among the 115 prescriptions, 76 was males and 39 were females. $?$ Another study conducted by Reddy CS et al., Out of 200 Patients from general medicine department, 134 (67\%) patients were male and $66(33 \%)$ patients were females, similar to study conducted and reported by Kaliamoorthy $K$ et $a . l$, that female patients was $61.81 \%$, males were $38.19 \%$.

In our study, Out of 110 study subjects, we found that a large number of patients were at the age group of more than $60 \mathrm{y}$ (29.1\%). A similar study conducted by Shankar PR et al., conducted in 252 patients among 20-30 y of age were admitted in the medicine department. Another study conducted by Gururaja MP et al., enrolled 400 inpatients in general medicine and surgical departments, Patients with age group greater than or equal to $60 \mathrm{y}$ received Cephalosporin's.
In total 110 patients prescriptions, 15 prescriptions were prescribed by generic names $13.6 \%$ and the rest 95 is prescribed by brand names $86.4 \%$. A study conducted by Kiran B et. al, found that $18.8 \%$ drugs were prescribed by their Generic name and the remaining 81.82\% were in Brand names. Another study conducted by Kaliamoorthy $K$ et al., in his study he found that 102 drugs $(28.02 \%)$ drugs were prescribed by their generic names. Generic prescribing helps the hospital pharmacy to have a better inventory control. Confusion among the pharmacists while dispensing can also be reduced when prescribed by generic names. Moreover, generic drugs are more cost-effective than the branded ones.

\section{CONCLUSION}

The present study showed more use of Non Essential medicines and Non-Generic (Branded) drugs. The prescription audit can be an eye opener for the prescribers. Such periodic audits should be conducted to rationalize the prescription, reduce errors and suggest effective management of antibiotics. The hospital administration can look into the issues in the hospital by implementing a formulary into the system so that physicians restrict their prescribing in generic names and effective therapy to the patients as essential drugs will be incorporated in hospital pharmacy. This study can help to provide feedback to the prescribers, thereby increasing the awareness and improve patient care by rational utilization of drugs. Age group of above 60 y was higher in number encoutered in our study. $3^{\text {rd }}$ generation cephalosporin's were mostly prescribed a class of drug. Mostly the prescription $86.4 \%$ was prescribed by brand name. Periodic evaluation of prescribing pattern is necessary to improve prescribing standards. There is a clear need for the development of standard treatment guidelines and educational initiatives to encourage the rational and appropriate drug use.

\section{AUTHORS CONTRIBUTIONS}

All the author have contributed equally

\section{CONFLICT OF INTERESTS}

Declared none 


\section{REFERENCES}

1. Kiran B, Ghufran MA, Kumar TSS, Kumar DS. The drug utilization of cephalosporins in a tertiary care hospital. World J Pharm Pharm Sci Dec 2016;5:1201-16.

2. Shankar PR, Subish P, Upadhayay D, Dubey AK, Deshpande VY. Cephalosporin utilization in the inpatient wards of a teaching hospital in western Nepal J Cap Inst Med 2005;27:7-12.

3. Gururaja MP, Sarah A, Samaga L, Joshi H, Nair S, Shastry CS Cephalosporin utilization evaluation in a university teaching hospital: a prospective study. J Drug Delivery Ther 2013;3:83-7.

4. Jyothi K, Babu JD. Drug utilization evaluation of cephalosporins in general medicine units of rural tertiary care hospital. Int J Curr Pharm Res 2012;4:88-91.

5. Drupad HS, Nagabushan H, Prakash GM. Prospective and observational study of antimicrobial drug utilization in medical intensive care unit in a tertiary care teaching hospital. Int J Pharmacol Res 2016;6:13-7.
6. Nagaraju K, Fard NM, Surekha G, Bolouri P. Drug utilisation evaluation of cephalosporins, macrolides, quinolones. Int J Res Pharm Chem 2014;4:841-9.

7. Pereira LMP, Phillips M, Ramlal H, Teemul K, Prabhakar P. Third-generation cephalosporin use in a tertiary hospital in Port of Spain, Trinidad: the need for an antibiotic policy. BMC Infect Dis 2004;4:59.

8. Masood H, Naqvi SB, Aslam N. Cost-effective analysis of different brands of ceftriaxone available in karachi, Pakistan. Pakistan J Pharmacol 2008;25:13-9.

9. Pandiamunian J, Somasundaram G. A study on prescribing pattern of antimicrobial agents in the medical intensive care unit of a tertiary care teaching hospital in puducherry union territory, South India. Int J Pharm Pharm Sci 2014;6:235-8.

10. Prashar D, Katyal R, Adiya AK. Pharmacoeconomical study of drug utilization pattern of third-generation cephalosporin with special reference to solan town. Int J Pharm Biol Sci 2014;4:109-12. 